\title{
2-Diazoacetoacetic acid, an efficient and convenient reagent for the synthesis of $\alpha$-diazo- $\beta$-ketoesters $\dagger$
}

\author{
Michael E. Meyer, Eric M. Ferreira and Brian M. Stoltz* \\ Received (in Bloomington, IN, USA) 13th December 2005, Accepted 27th January 2006 \\ First published as an Advance Article on the web 15th February 2006 \\ DOI: $10.1039 / \mathrm{b5} 17719 \mathrm{~g}$
}

The formation of various $\alpha$-diazo acetoacetic esters can be obtained in a single transformation with good to excellent yields using readily available 2 -diazoacetoacetic acid.

Diazo carbonyl compounds are versatile building blocks in organic synthesis. ${ }^{1}$ The unique reactivity of these compounds allows them to undergo a variety of synthetic transformations that include $\mathrm{C}-\mathrm{H}$ insertions, ${ }^{2}$ Wolff rearrangements, ${ }^{3}$ cyclopropanations, ${ }^{4}$ and other useful transformations. ${ }^{5}$ Over the past three decades, the utility and scope of diazo carbonyl compounds have vastly increased due to the development of various transition metal catalysts that can control the chemoselectivity and regioselectivity of a given reaction. ${ }^{6}$

In the course of recent synthetic studies, we required compounds of the general type $\mathbf{2}$. We envisioned that accessing enone $\mathbf{2}$ from alcohol 1 via standard protocols would be difficult due to conjugate addition reactions of the enone to form undesired products. Indeed, initial attempts to prepare $\mathbf{2}$ were unsuccessful using known protocols (Fig. 1). For instance, coupling of alcohol 1 with diketene, followed by diazotization using $p \mathrm{ABSA}^{7}$ with TEA led only to decomposition. ${ }^{8}$ The synthesis of $\mathbf{2}$ via a transesterification route was also explored. However, treatment of alcohol 1 with methyl diazoacetoacetate (3) and dimethylaminopyridine (DMAP) in toluene at $110{ }^{\circ} \mathrm{C}$ produced none of the desired diazoester 2., ${ }^{9,10}$

It thus became apparent that compound $\mathbf{2}$ could not be produced under basic conditions using known methods, and an alternate strategy was required. We envisioned that 2-diazoacetoacetic acid (4) could, in principle, be coupled to alcohols using standard carbodiimide chemistry. A related system has been

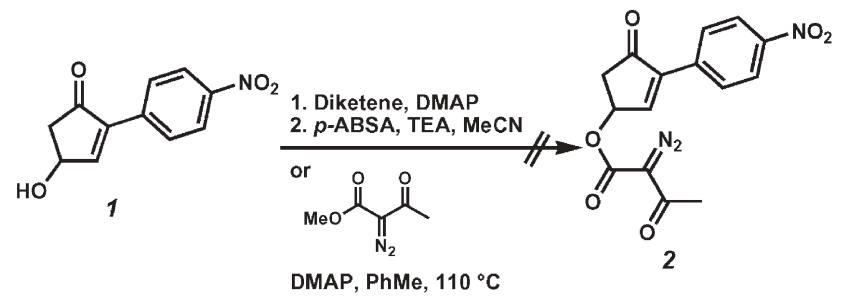

Fig. 1 Initial attempts toward 2

Division of Chemistry and Chemical Engineering, California Institute of Technology, 1200 East California Boulevard, MC 164-30, Pasadena, CA, 91125, USA.E-mail: stoltz@caltech.edu; Fax: 626564 9297;

Tel: 6263956064

† Electronic supplementary information (ESI) available: experimental details and characterization data for all compounds. See DOI: 10.1039/ b517719g employed by Kato for the preparation of nonsymetrical diazomalonates by implementation of the mono-acid derived from ethyl diazomalonate. ${ }^{11}$ Attempts to saponify ethyl diazoacetoacetate under identical conditions to those reported by Kato led only to decomposition. As an alternative, we hypothesized that it could be possible to obtain 2-diazoacetoacetic acid (4) by careful hydrogenolysis of a benzyl ester without loss of $\mathrm{N}_{2}$. Gratifyingly, hydrogenolysis under neutral conditions occurred smoothly in THF at room temperature using $10 \% \mathrm{Pd} / \mathrm{C}(7 \% \mathrm{w} / \mathrm{w})$ as catalyst to provide a crude solution of diazoacetoacetic acid (4) and $c a$. $2-5 \%$ of acetoacetic acid after filtration (Fig. 2). ${ }^{12}$

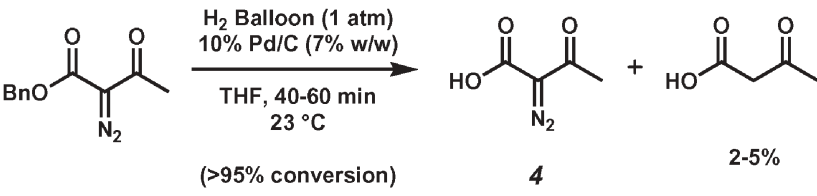

Fig. 2 Generation of 2-diazoacetoacetic acid.

With diazo acid $\mathbf{4}$ in hand, we hoped that direct coupling under neutral conditions would afford ester $\mathbf{2}$ in high yield. To our delight, coupling of $\mathbf{4}$ with alcohol $\mathbf{1}$ proceeded rapidly upon treatment with DCC and a catalytic amount of DMAP to provide ester 2 in 77\% yield (Table 1, entry 1). We then investigated the scope of the esterification with a number of alcohols. ${ }^{13}$ As shown in Table 1, esterification occurs efficiently for a variety of alcohols. Primary and allylic alcohols couple with diazoacetoacetic acid in good to excellent yields (entries 3-7). Secondary alcohols are also competent substrates and lead to their respective $\alpha$-diazo$\beta$-ketoesters in good yields (entries 1, 2, 9-11). ${ }^{14}$ As shown in entry 8, 3-methoxyphenol undergoes esterification with $\mathbf{4}$ in 75\% yield. Amines are also tolerated under these conditions, as illustrated by the coupling of $\mathbf{4}$ with phenethylamine to afford the $\alpha$-diazo- $\beta$-ketoamide in $95 \%$ yield (entry 12 ). ${ }^{15}$

In conclusion, a general method for obtaining $\alpha$-diazoacetoacetic esters using 2-diazoacetoacetic acid (4) has been described. The latter reagent is readily generated, and can be synthesized on reasonable scale $(c a .5 .0 \mathrm{mmol})$ in a straightforward manner from available starting materials. Coupling with acid $\mathbf{4}$ offers several advantages over known methods. Mainly, it allows diazo incorporation under neutral conditions into base-sensitive substrates that could not be diazotized under known basic conditions. Furthermore, esterification with $\mathbf{4}$ is more convergent than the general method of acylation with diketene followed by diazotization, as the substrate undergoes only a single transformation to obtain the diazo dicarbonyl. The coupling of 2-diazoacetoacetic acid (4) provides the desired products in good to excellent yields 
Table 1 Coupling of 2-diazoacetoacetic acid ${ }^{a}$

\begin{tabular}{llll}
\hline Entry & Substrate & Product & Yield $^{b}$ \\
\hline $1^{c, d}$ & &
\end{tabular}

2<smiles>O=C1CC(O)C=C1c1ccccc1</smiles>

5

3

4
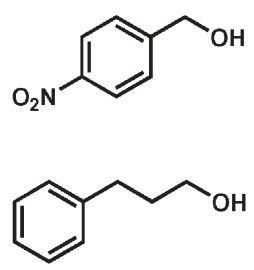

5

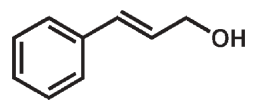

6

$\mathrm{Me}_{8} \mathrm{OH}$

7

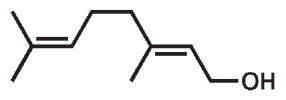

$8^{d}$

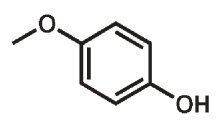

$9^{d}$

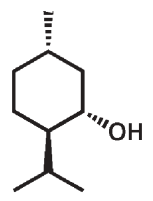

$10^{d}$

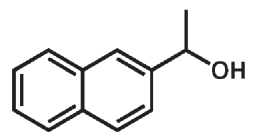

$11^{d}$

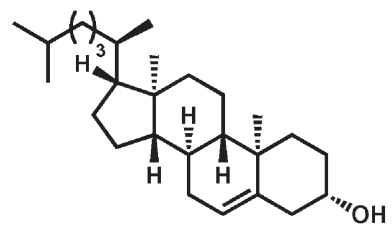

12<smiles>NCCc1ccccc1</smiles><smiles>CC(=O)C(=N)C(=O)OC1C=C(c2ccccc2)C(=O)C1</smiles>

95

92<smiles>CC(=O)C(=N)C(=O)OCc1ccc([N+](=O)[O-])cc1</smiles>

85
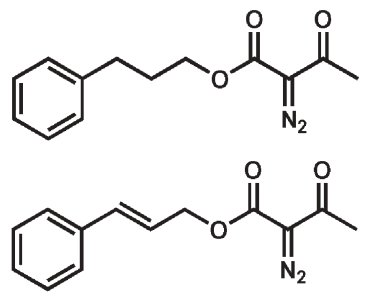

82

Metro

80

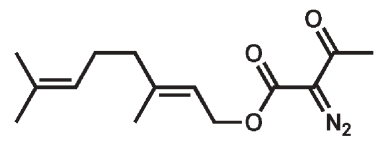

$\underbrace{2}_{\mathrm{N}_{2}}$

75<smiles>CC(=O)C(=N)C(=O)O[C@H]1C[C@H](C)CCC1C(C)C</smiles>

77

81

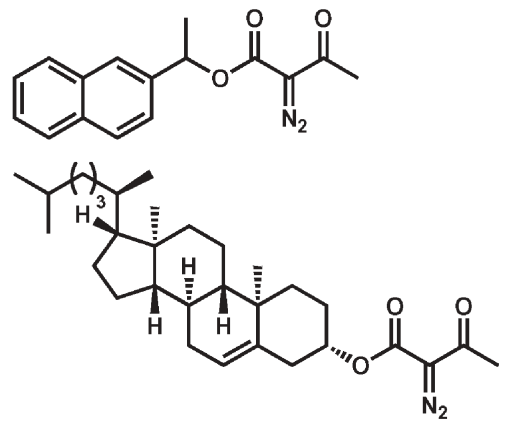

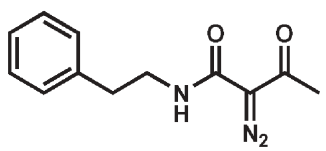

77

87

95

${ }^{a}$ Standard conditions: $0.50 \mathrm{mmol}$ substrate, 2-diazoacetoacetic acid (2.2 equiv), DCC (2.0 equiv), DMAP $\left(0.10\right.$ equiv), $3.30 \mathrm{~mL} \mathrm{CH}_{2} \mathrm{Cl}_{2}, 23{ }^{\circ} \mathrm{C}$, $60-90$ min. ${ }^{b}$ Isolated yield. ${ }^{c} 0.30 \mathrm{mmol}$ substrate. ${ }^{d}$ Reaction at $40{ }^{\circ} \mathrm{C}, 60-90 \mathrm{~min}$.

This journal is (c) The Royal Society of Chemistry 2006

Chem. Common., 2006, 1316-1318 | 1317 
and tolerates a wide range of alcohols. In addition, amines can be used as substrates for the amidation with $\mathbf{4}$, thus providing access to $\alpha$-diazo- $\beta$-ketoamides. The use of diazo ketoacids as coupling partners in various synthetic efforts is currently being employed in our laboratory.

The authors gratefully acknowledge the NSF (predoctoral fellowship for E.M.F.), Bristol-Myers Squibb (Graduate Fellowship in Synthetic Organic Chemistry to E.M.F.), AstraZeneca, Boehringer Ingelheim, Johnson \& Johnson, Pfizer, Merck, Amgen, Research Corporation, Roche, the Dreyfus Foundation, and GlaxoSmithKline for generous funding.

\section{Notes and references}

1 For reviews, see: (a) M. P. Doyle, M. A. McKervey and T. Ye, Modern Catalytic Methods for Organic Synthesis with Diazo Compounds from Cyclopropanes to Ylides; Wiley-Interscience: New York, New York, 1998; (b) T. Ye and M. A. McKervey, Chem. Rev., 1994, 94, 1091-1160; (c) A. Padwa and D. Austin, Angew. Chem., Int. Ed. Engl., 1994, 33, 1797-1815; (d) M. P. Doyle, Chem. Rev., 1986, 86, 919-939.

2 For a recent review of $\mathrm{C}-\mathrm{H}$ activation using diazo compounds, see: H. M. L. Davies and R. E. J. Beckwith, Chem. Rev., 2003, 103, 2861-2904.

3 For recent examples of Wolff rearrangements, see: $(a)$ R. Sarpong, J. T. Su and B. M. Stoltz, J. Am. Chem. Soc., 2003, 125, 13624-13625; (b) H. Yang, K. Foster, C. R. J. Stephenson, W. Brown and E. Roberts, Org. Lett., 2000, 2, 2177-2179; (c) R. R. Julian, J. A. May, B. M. Stoltz and J. L. Beauchamp, Angew. Chem., Int. Ed., 2003, 42, 1012-1015; (d) A. Bogdanova and V. Popik, J. Am. Chem. Soc., 2003, 125, 1456-1457; (e) J. Podlech and M. R. Linder, J. Org. Chem., 1997, 62, 5873-5883.

4 For a review of cyclopropanation, see: H. Lebel, J.-F. Marcoux, C. Molinaro and A. B. Charette, Chem. Rev., 2003, 103, 977-1050.

5 For selected examples, see: (a) S. Kitagaki, M. Anada, O. Kataoka, K. Matsuno, C. Umeda, N. Watanabe and S.-I. Hashimoto, J. Am. Chem. Soc., 1999, 121, 1417-1418; (b) J. A. May and B. M. Stoltz, J. Am. Chem. Soc., 2002, 124, 12426-12427; (c) J. L. Wood, G. A. Moniz, D. A. Pflum, B. M. Stoltz, A. A. Houbec and H.-J. Dietrich, J. Am. Chem. Soc., 1999, 121, 1748-1749; (d) A. Padwa, M. A. Brodney, J. P. Marino, Jr., M. H. Osterhout and A. T. Price, J. Org. Chem., 1997, 62, 67-77.

6 (a) A. Padwa, D. J. Austin and S. F. Hornbukle, J. Org. Chem., 1996, 61, 63-72; (b) C. H. Yoon, M. J. Zaworotko, B. Moulton and
K. W. Jung, Org. Lett., 2001, 3, 3539-3542; (c) A. G. H. Wee, B. Liu and L. Zhang, J. Org. Chem., 1992, 57, 4404 4414; (d) A. Padwa, D. J. Austin, A. T. Price, M. A. Semones, M. P. Doyle, M. N. Protopopova, W. R. Winchester and A. Tran, J. Am. Chem. Soc., 1993, 115, 8669-8680.

7 J. S. Baum, D. A. Shook, H. M. L. Davies and D. H. Smith, Synth. Commun., 1987, 17, 1709-1716.

8 We have tentatively assigned the product of this reaction sequence to be:

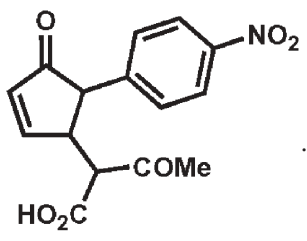

i

9 A similar transesterification on a $2^{\circ}$ alcohol was recently described, see: J. Lim, D.-J. Choo and Y. H. Kim, Chem. Commun., 2000, 553-554.

10 When alcohol 5 was subjected to the identical reaction conditions, the only isolated product arose from a Wolff Rearrangement of $\mathbf{3}$, followed by addition of $\mathbf{5}$ into the resulting ketene to provide ii
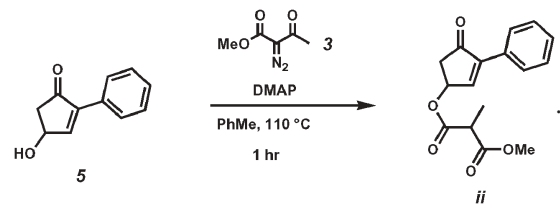

11 F. Kido, K. Yamaji, T. Abiko and M. Kato, J. Chem. Res. (S), 1993, 18-19.

12 For a typical hydrogenolysis, see Supporting Information.

13 For a typical esterification procedure, see Supporting Information.

14 It is known that $\alpha$-diazoacetoacetates can be converted to $\alpha$-diazoacetates under basic conditions. For a general procedure, see: M. P. Doyle, R. E. Austin, A. S. Bailey, M. P. Dwyer, A. B. Dyatkin, A. V. Kalinin, M. M. Y. Kwan, S. Liras, C. J. Oalmann and R. J. Pieters, et al., J. Am. Chem. Soc., 1995, 117, 5763-5775.

15 For examples of $\alpha$-diazo- $\beta$-ketoamides, see: (a) A. Padwa and L. Zhi, J. Am. Chem. Soc., 1990, 112, 2037-2038; (b) A. Jeganathan, S. K. Richardson, R. S. Mani, B. E. Haley and D. S. Watt, J. Org. Chem., 1986, 51, 5362-5367; (c) A. Padwa, D. C. Dean, D. J. Fairfax and S. L. Xu, J. Org. Chem., 1993, 58, 4646-4655. 